\title{
NF- $\mathrm{KB}$ signaling in skeletal muscle: prospects for intervention in muscle diseases
}

\author{
Foteini Mourkioti $\cdot$ Nadia Rosenthal
}

Received: 26 September 2007 /Revised: 23 November 2007 / Accepted: 10 December 2007 / Published online: 2 February 2008

(C) The Author(s) 2008

\begin{abstract}
Muscle remodeling is an important physiological process that promotes adaptive changes in cytoarchitecture and protein composition after exercise, aging, or disease conditions. Numerous transcription factors have been reported to regulate skeletal muscle homeostasis. NF-KB is a major pleiotropic transcription factor modulating immune, inflammatory, cell survival, and proliferating responses; however, its role in muscle development, physiology, and disease has just started to be elucidated. The current review article aims to summarize the literature on the role of NF-KB signaling in skeletal muscle pathophysiology, investigated over the last years using in vitro and more recently in vivo systems. Understanding the exact role of NF-KB in muscle cells will allow better therapeutic manipulations in the setting of human muscle diseases.
\end{abstract}

Keywords NF- $\mathrm{kB}$ transcription factor .

Genetic and pharmacological models · Muscle diseases

\section{NF-KB signaling pathway}

Nuclear factor $\mathrm{kb}(\mathrm{NF}-\mathrm{kB})$ transcription factors are evolutionary conserved signaling molecules that play a critical role in many biological processes, including innate and adaptive immunity [1], tumorogenesis [2], as well as tissue development and disease [3-9]. Mammalian cells have five NF-kB family members, RelA (p65), cRel, RelB, p50/p105

F. Mourkioti $(\varangle) \cdot$ N. Rosenthal EMBL Mouse Biology Unit, Campus “A. Buzzati-Traverso”, via Ramarini 32,

00015 Monterotondo-Scalo (RM), Italy

e-mail: fmourkioti@embl-monterotondo.it

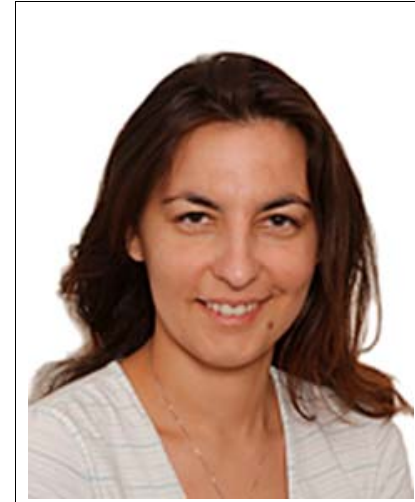

FoteInI MOURKIOTI received her $\mathrm{PhD}$ from MaxPlanck Institute for Biophysical Chemistry, Department Molecular Developmental Biology, Goettingen, Germany. She is currently a postdoctoral fellow at EMBL, Mouse Biology Unit, Monterotondo, Italy. Her research interests include the role of inflammatory pathways, especially NF- $\mathrm{KB}$ signaling, in the regulation of muscle and heart pathophysiology.

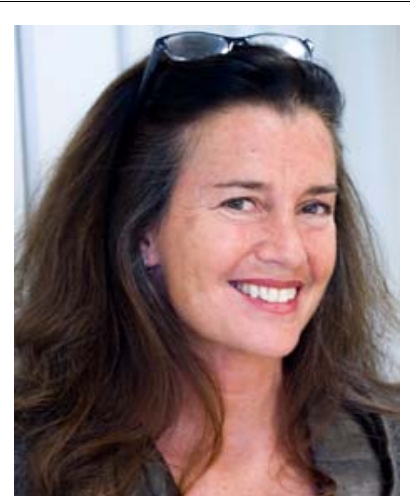

Nadia Rosenthal received her $\mathrm{PhD}$ from Harvard Medical School (Biochemistry), Boston, USA. She is presently the director of EMBL Mouse Biology Unit in Monterotondo, Italy and the scientific director of Imperial College London, National Heart and Lung Institute, Harefield Heart Science Centre. Her research interests focus on muscle gene regulation and the biology and enhancement of muscle and cardiovascular regeneration.
(NF-kB1), and p52/p100 (NF-kB2) [10]. Each member of the NF-KB transcription factor family, besides RelB, can form homodimers as well as heterodimers with one another [1]. All NF- $\mathrm{kB}$ subunits are characterized by a highly conserved 300 amino acid N-terminal domain, called Rel homology domain (RHD), that mediates (a) binding to promoters and enhancer regions containing $\mathrm{KB}$ sites $\left(5^{\prime}\right.$ GGGRNNYYCC3', N=any base, $\mathrm{R}=$ purine, and $\mathrm{Y}=$ pyrimidine) [11], (b) subunit dimerization, and (c) interaction 
with inhibitory proteins, known as IKBs [12]. NF- $\kappa B$ complexes act either as inducers or repressors of gene expression [11]. The main transcriptional activated forms of NF- $k B$ are the heterodimers $\mathrm{p} 65 / \mathrm{p} 50$ or $\mathrm{p} 65 / \mathrm{p} 52$ [11], while homodimers such as $\mathrm{p} 50 / 50$ or $\mathrm{p} 52 / \mathrm{p} 52$ are transcriptionally repressive [1, 13].

NF-KB-mediated signaling has been most extensively studied in the immune system. In the vast majority of unstimulated cells, NF-KB dimers are retained in the cytoplasm through association with IkBs. There are five

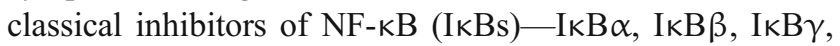
$\mathrm{I} \kappa \mathrm{B} \varepsilon$, and $\mathrm{Bcl}-3$, which contain ankyrin (ANK) repeats and a 33 amino acid motif responsible for mediating proteinprotein interaction [1, 11]. Since p100 and p105 also contain ANK repeats, they can function as IKB-like proteins, besides their role as NF- $\mathrm{kB}$ nuclear transcription factors $[14,15]$. Although the biological relevance of the different IKB proteins has still to be explored in depth [1], their most common function is binding to NF- $\mathrm{KB}$ dimers to regulate the shuttling between the cytoplasm and nucleus [16]. The balance between cytoplasmic and nuclear localization is altered upon $\operatorname{IKB} \alpha$ degradation since it removes the contribution of the I $\mathrm{B}$ nuclear export sequence (NES) and exposes the masked NLS of the NF$\mathrm{KB}$ subunits, resulting in predominantly nuclear localization of NF-KB [17]. Finally, Bcl-3 is an unusual member of the IKBs, which interacts specifically with $\mathrm{p} 50$ and p52 homodimers and, in contrast to the other IKBs, induces the expression of NF-kB-regulated genes [18]. The different components of the pathway, as discussed in the following paragraphs, are schematically illustrated in Fig. 1.

The rapid activation and nuclear translocation of cytoplasmic NF-KB, in the "classical" or "canonical" pathway, is the result of phosphorylation of the inhibitory IKB by the activated IKB kinase (IKK) complex [19]. The IKK complex consists of two catalytic subunits, named IKK $\alpha /$ IKK1 and IKK $\beta /$ IKK2 [20] and one regulatory subunit, named NF-kB essential modulator (IKK $\gamma / \mathrm{NEMO}$ ) [21]. Upon encountering a variety of stimuli, including tumor necrosis factor- $\alpha$ (TNF- $\alpha$ ), interleukin-1 (IL-1), and other growth factors, $\mathrm{I} \kappa \mathrm{B} \alpha$ is phosphorylated and degraded through the ubiquitination pathway, rendering NF- $\mathrm{kB}$ free to translocate to the nucleus and bind to its target genes [10] (Fig. 1).

The ubiquitin-proteasome pathway controls the mode of activation of NF- $\mathrm{KB}$, since phosphorylation is required for the ubiquitination of $\operatorname{I} \kappa \mathrm{B} \alpha$. Interestingly, the ubiquitin pathway is also implicated in the proteolysis of p100 and p105 [22]. Moreover, recent studies have also identified several ubiquitin pathway components that function upstream of IKK subunits, including the TRAF proteins as E3 ubiquitinase ligases and $\mathrm{TAB} 2$ and $\mathrm{TAB} 3$ as ubiquitin receptors (discussed in [22]). The mechanism that under- lines the formation of polyubiquitin chains as well as the different ubiquitin-conjugated enzymes (E2s) or ubiquitinprotein ligases (E3s) involved in the ubiquitin-proteasome and control NF- $\mathrm{KB}$ pathway remains to be fully elucidated.

Some NF- $\mathrm{kB}$ activators, such as B cell-activating factor of the TNF family (BAFF), lipopolysaccharide (LPS), stimulation of CD40 and lymphotoxin- $\beta$ receptors and latent membrane protein-1 of Epstein-Barr virus, can activate the "non-canonical" or "alternative" pathway [23]. In this case, activation of NF-KB-inducing kinase (NIK) results in homodimerization of IKK $\alpha$, which then phosphorylates the p100 NF- $\mathrm{KB}$ subunit, inducing its proteolytic processing to $\mathrm{p} 52$. As a consequence, activated $\mathrm{p} 52 /$ RelB heterodimers enter the nucleus and target distinct $\mathrm{kB}$ elements [19] (Fig. 1).

Besides the NF-kB-dependent effects of IKKs, more functions for IKKs that are independent from the NF- $\mathrm{KB}$ pathway have been described. For example, IKK $\alpha$ can phosphorylate histone $\mathrm{H} 3$ [24], through interaction with the transcriptional co-activator cyclic AMP-responsive element binding (CREB)-binding protein (CBP) [25]. IKK $\alpha$ also seems to regulate cyclin D1 expression through other mechanisms, including phosphorylation and activation of the estrogen receptor- $\alpha(E R \alpha)$ transcription factor [26], phosphorylation and stabilization of $\beta$-catenin [27], or even direct phosphorylation of cyclin D1 protein [28]. Moreover, IKK $\alpha$ could have other effects, independent of NF-KB activation, in keratinocyte differentiation $[8,29]$ and tooth development [30]. Such independent functions have also been proposed for the IKK $\beta$ subunit. Specifically, IKK $\beta$ has been shown to phosphorylate and inhibit FOXO3a, resulting in the enhancement of IKK-dependent induction of tumorogenesis in mammary glands [31]. IKK $\beta$ can also phosphorylate 14-3-3 $\beta$ and inhibit TPP-14-3-3 $\beta$ ARE binding and might therefore regulate mRNA stability [32]. In the same context, IKK $\gamma$ (NEMO) subunit has also the ability to translocate to the nucleus following DNA damage and stimulate the interaction of CBP with hypoxiainducible factor- $2 \alpha$ (HIF- $2 \alpha$ ), enhancing the transcriptional activity of HIF-2 $\alpha$ [33]. These independent effects of the IKK subunits (Fig. 1) have recently evolved, and further investigation is needed to define the exact mechanisms that allow action through NF-kB-independent activation.

But which are the upstream signaling pathways that lead to IKK or NF-KB activation? Different signals, such as TNF, interleukins, and various stress signals, all activate the IKK complex. More specifically, activation of the TNF receptor results in its trimerization and recruitment of the adaptor protein TRADD (TNF receptor associated via death domain), which, in turn, interacts with TRAF2 (TNFreceptor-associated factor 2). Consequently, receptor-interacting protein (RIP) and MAP/ERK kinase kinase 3 (MEKK3) link TNF signaling to IKK activation [16] (Fig. 1). In addition, specific receptors, which lead to IKK 
activation, recognize many pathogen substrates such as LPS, lipoproteins, or other compounds [1]. The most common pathogen receptors are the Toll-like receptors (TLR) and so far ten members of the TLR family have been reported [34]. LPS binding to TLRs activates an intracellular signaling cascade that involves recruitment of MYD88 (myeloid differentiation primary response gene 88) and IRAK (interleukin-1-receptor-associated kinase), phosphor- ylation of TRAF6 (TNF-receptor-associated factor 6), which then signals through the TAB2-TAK1-TAB1 complex to activate the IKK complex [34] (Fig. 1). Moreover, in peripheral $\mathrm{T}$ cells, $\mathrm{T}$ cell receptors (TCRs) are responsible for activation of the NF-KB pathway [16]. T cell stimulation results in $\mathrm{PKC} \theta$ activation (protein kinase $\mathrm{C} \theta$ ), which signals via the CARMA1-BCL-10-MALT1 complex to activate the IKK complex [16] (Fig. 1).

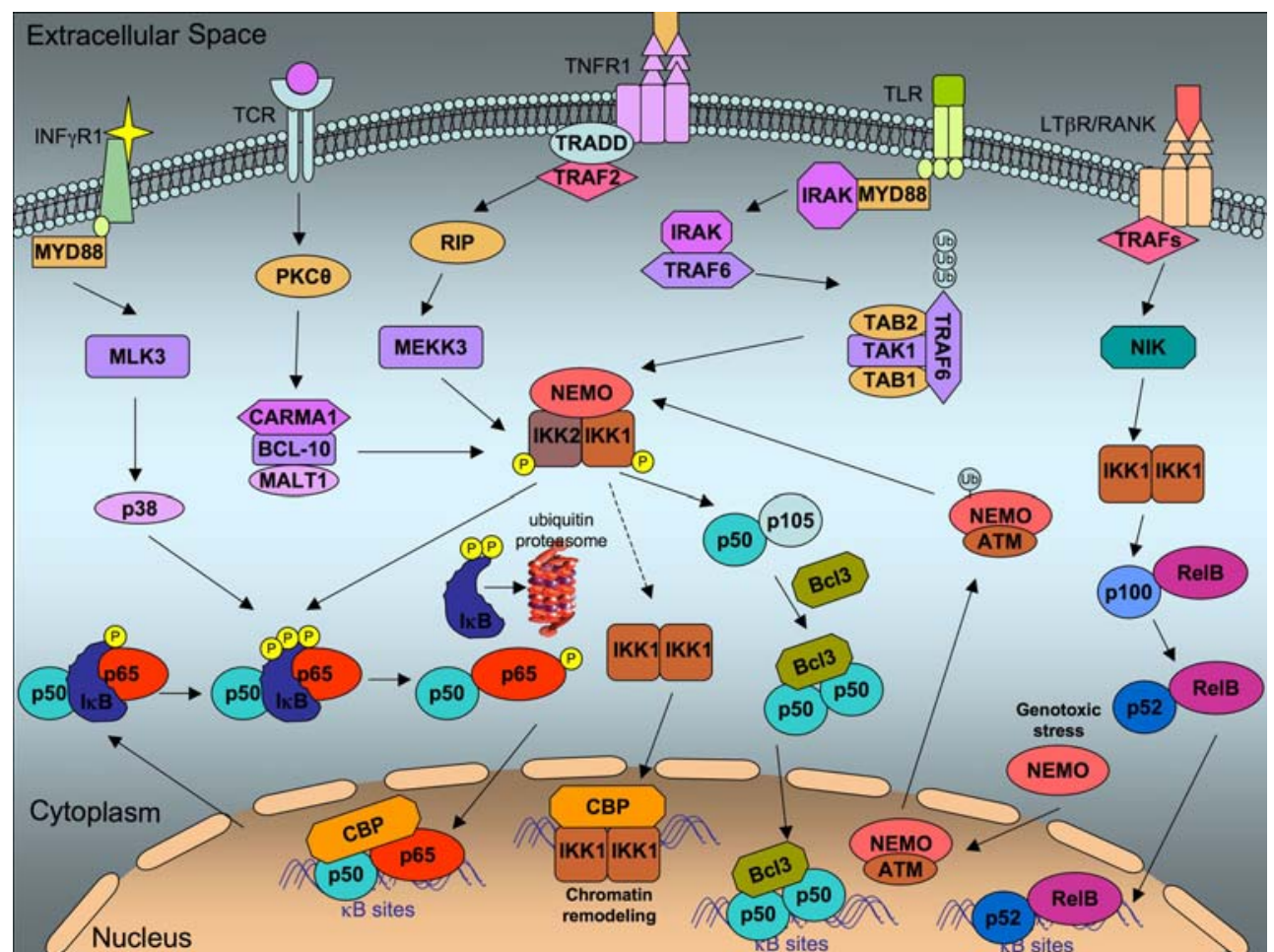

Fig. 1 An outline of major signaling pathways leading to NF- $k B$ activation. The best characterized NF- $\mathrm{KB}$ activators include TCR signaling, TNF, TLR, LT $\beta \mathrm{R}$, and INF- $\gamma \mathrm{R}$ signaling. Activation of TNF receptor results in its trimerization and recruitment of the adaptor protein TRADD, which, in turn, interacts with TRAF2. Consequently, RIP and MEKK3 link TNF signaling to IKK activation. LPS binding to TLRs activates an intracellular signaling cascade that involves recruitment of MYD88 and IRAK, phosphorylation of TRAF6, which then signals through the TAB2-TAK1-TAB1 complex to activate the IKK complex. In peripheral T cells, T cell stimulation results in PKC $\theta$ activation, which signals via the CARMA1-BCL-10-MALT1 complex to activate the IKK complex. INF- $\gamma$ R1 can recruit MyD88, and through MLK3 activates p38. Convergence point for most of the above cascades is the activated IKB kinase (IKK) complex, which consists of three subunits: IKK1, IKK2, and NEMO. Upon IKK activation, $I \kappa B \alpha$ is phosphorylated and degraded through the ubiquitination pathway, rendering NF- $\mathrm{kB}$ free to translocate to the nucleus and bind to its target genes (canonical pathway). In other cases, IKK stimulation leads to $\mathrm{p} 105 / \mathrm{p} 50$ activation and subsequent binding of $\mathrm{Bcl} 3$ to the $\mathrm{p} 50 / \mathrm{p} 50$ homodimers. The $\mathrm{p} 50 / \mathrm{p} 50-\mathrm{Bcl} 3$ complex translocates to the nucleus and induces NF- $\mathrm{KB}$ dependent transcription. Some activators such as BAFF or LPS can activate the non-canonical pathway. Here, activation of NF- $\mathrm{KB}$-inducing kinase (NIK) results in homodimerization of IKK1, which then phosphorylates the p100 NF-KB subunit, inducing its proteolytic processing to p52. Besides their NF- $\mathrm{kB}$-dependent effects, more functions independent of the NF-kB pathway have been described for IKKs. IKK1 can phosphorylate histone $\mathrm{H} 3$, through interaction with the transcriptional co-activator CBP. NEMO has also the ability to translocate to the nucleus following DNA damage. Nuclear NEMO is sumoylated and then ubiquitinated, in a process that depends on ATM kinase. Then, NEMO together with ATM translocate to the cytoplasm where it activates IKK2. TCR T cell receptor, TNFR tumor necrosis factor receptor, TLR Toll-like receptor, $I N F-\gamma R 1$ : interferon- $\gamma$ receptor 1 , $R A N K$ receptor activator of $\mathrm{NF}-\mathrm{kB}, P K C \theta$ protein kinase $\mathrm{C} \theta$, CARMA1 caspase-associated recruitment domain-1, BCL-10 B cell lymphoma 10, MALT1 mucosa-associated lymphoid tissue lymphoma translocation gene 1, MEKK3 MAP/ERK kinase kinase 3, RIP receptor-interacting protein, TRADD TNF receptor associated via death domain, TRAF TNF-receptor-associated factor, IRAK interleukin-1-receptor-associated kinase, MYD88 myeloid differentiation primary response gene 88, TAK 1 transforming-growth-factor- $\beta$-activated kinase 1, TAB1 TAK1-binding protein 1, TAB2 TAK1-binding protein 2, $A T M$ ataxia-telangiestasia-mutated kinase, $I \kappa B$ inhibitor of $\mathrm{\kappa B}, I K K$ IкB kinase, $N E M O \mathrm{NF}-\mathrm{kB}$ essential modulator, $U b$ ubiquitin, NIK NF-kB-inducing kinase, $M L K 3$ mixed-lineage kinase 3, $C B P$ CREB-binding protein, $B C L-3 \mathrm{~B}$ cell lymphoma $3, T C R \mathrm{~T}$ cell receptor, $T N F$ tumor necrosis factor, $L T \beta R$ lymphotoxin- $\beta$ receptor, $I N F-\gamma R$ interferon- $\gamma$ receptor 
From this overview, it is clear that cells of the immune system have been particularly advantageous for elucidating a large number of NF- $\mathrm{KB}$ regulatory mechanisms. The presence of different activators, the variety of I $K B$ proteins, NF- $\mathrm{KB}$ dimers, and post-transcriptional modifications of the $N F-\kappa B$ subunits, together with the crosstalk with other transcription factors and the independent effects of the IKKs, reflect the high diversity of this pathway, which is not limited to the immune system alone.

\section{Role of NF-KB in muscle formation}

The IKK/NF-KB signaling cascade and the mechanisms that regulate it have not been explored in as much depth in other cell types. The importance of NF- $\mathrm{KB}$ signaling in tissues, such as liver $[35,36]$, brain $[7,37,38]$, and skin $[6$, $8,39-41]$, has only recently received attention. Concomitantly, the potential contribution of the NF- $\mathrm{KB}$ pathway during muscle development has also started to emerge over the last years and this review will discuss the literature on the contribution of NF- $\mathrm{KB}$ in skeletal muscle formation.

Muscle is the contractile tissue of the body, which functions via force production to cause movements of all body parts. Studies using muscle cell lines revealed that p65 is abundant in rat L6 muscle cell nuclei [42], while murine $\mathrm{C} 2 \mathrm{C} 12$ skeletal muscle cell lines contain $\mathrm{p} 65 / \mathrm{p} 50$ in their nuclei [43]. Although the p65/p50 heterodimer is the most commonly studied form of NF-kB, recently, other combinations have been revealed in skeletal muscles from viable total knockout mice of various NF- $\mathrm{KB}$ subunits. cRel protein is expressed in low levels in skeletal muscle

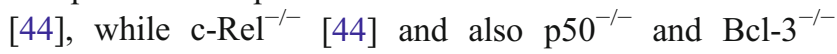
muscles [45] do not show differences in NF- $\mathrm{kB}$ activity or fiber morphology under state-stage conditions, indicating that these NF- $\mathrm{kB}$ subunits are not highly important during muscle development. However, upon disease conditions, such as unloading-induced atrophy, complexes comprising p50 and Bcl-3 subunits [45], but not c-Rel [44], are activated and translocate into the nucleus in order to regulate transcription of target genes.

Concerning the target genes of NF-KB activation in skeletal muscle, it was described that in the $\mathrm{C} 2 \mathrm{C} 12$ myoblast cell line, NF- $\mathrm{kB}$ binds on $\mathrm{kB}$ sites of the cyclin D1 promoter, regulates its transcription [43], and leads to progression into the $\mathrm{S}$ phase of cell cycle. The binding activity of NF-KB on cyclin D1 is reduced during myogenesis, suggesting that NF- $\mathrm{KB}$ plays an important role for transition from the proliferation to the differentiation stage [43]. The notion that NF- $\mathrm{kB}$ acts as a negative regulator of late-stage muscle differentiation was supported by recent demonstration that the $\mathrm{p} 65 / \mathrm{p} 50$ heterodimer complex binds to the transcriptional repressor YinYang1 (YY1) and results in inhibition of skeletal myogenesis, via transcriptional silencing of myofibrillar genes [46]. Interestingly, transcriptional regulation of NF- $\mathrm{KB}$ depends on the muscle's state. It was shown that upon atrophy conditions, NF- $\mathrm{KB}$ binds on the promoter of murine ring finger-1 (MuRF1) [4], an E3 ubiquitin ligase known to be involved in multiple models of skeletal muscle atrophy [47], and increases its expression, supporting the notion that $\mathrm{NF}-\mathrm{KB}$ can also regulate the ubiquitin pathway. Although MuRF1 is not the only critical mediator of muscle atrophy [4], additional NF- $\mathrm{KB}$ muscle targets in this pathway have not yet been described.

In addition to the identification of transcriptional NF- $\mathrm{KB}$ targets, potential upstream activators of NF- $\mathrm{kB}$ in skeletal muscle function have been extensively studied. Different research laboratories [48-58] have analyzed the effect of TNF- $\alpha$ in muscles. TNF- $\alpha$ is also called cachectin because it was found in the urine of cancer patients who suffer from muscle cachexia [59], a syndrome characterized by extreme weight loss and body wasting. Although TNF knockout mice do not show any distinct muscle phenotype under state-stage conditions [48], when human recombinant TNF was added to proliferating myoblasts, cell fusion as well as muscle differentiation was inhibited [58]. Interestingly, TNF- $\alpha$ inhibition of myogenesis was mediated through repressed synthesis of MyoD at the post-transcriptional level [60]. Similarly, recent studies showed that treatment of C2C12 myoblasts with TNF-like weak inducer of apoptosis (TWEAK) resulted in NF- $\mathrm{KB}$ activation and degradation of MyoD protein [49]. Consistently, two downstream regulators of the TNF- $\alpha$ pathway, namely receptor-interacting protein 2 (RIP2) and TNF-associated factor 2 (TRAF2), also negatively regulate myogenesis [61-63] (Fig. 2).

A new mechanism has recently emerged whereby TNF$\alpha$ inhibits muscle differentiation through activation of caspases in the absence of apoptosis [54]. Expression of both PW1 and Bax is required to mediate this response. PW1 (also named as paternally expressed gene 3 or Peg3 [64]) is expressed at high levels both in developing skeletal muscle and in muscle cell lines. PW1 interacts with TRAF2 and participates in the TNF- $\alpha$ signal transduction pathway $[65,66]$. Although the exact function of PW1 in muscle cells is not yet completely understood, this study implies that the interaction of TRAF2 with PW1 induces translocation of some components of cell death effectors (such as Bax proteins) in mitochondria and activation of caspases [54] (Fig. 2).

Besides its role in myogenic differentiation, TNF- $\alpha$ is also important for the activation of satellite cells during muscle regeneration [50]. Interestingly, a key activator during this process is believed to be the MAP kinase p38 [50] (Fig. 2), a protein that controls skeletal muscle differentiation [67], although the exact downstream targets of TNF- $\alpha$, which lead to p38 activation, remain to be 
established. It is likely that upon injury, TNF- $\alpha$ activates satellite cells to enter the cell cycle and accelerates G1-to-S phase transition, involving activation of early response genes [57].

Moreover, TNF- $\alpha$ appears to stimulate general proteolysis by increasing ubiquitin conjugation to muscle proteins [68]. In this process, the ubiquitin-activating enzyme (E1 protein) activates ubiquitin, which is then transferred to an ubiquitin carrier protein (E2). The ubiquitin carrier protein interacts with an ubiquitin ligase (E3) to catalyze transfer of ubiquitin to the protein substrate, marking the substrate for proteasome degradation as ubiquitin accumulates [69]. According to the proposed mechanism, the TNF- $\alpha / N F-k B$ pathway promotes the loss of muscle protein through increased transcription of an E2 ubiquitin carrier protein that called $\mathrm{UbcH} 2 / \mathrm{E} 2_{20 \mathrm{k}}$ gene [68]. Although it was suggested that $\mathrm{UbcH} 2$ interacts with one or more ubiquitin ligases [68], it still remains unclear whether this interaction can occur with known NF- $\mathrm{KB}$ candidates of muscle atrophy such as MuRF1 [4].

Aside from the TNF- $\alpha$ signaling pathway, few studies have also looked into the role of other cytokines during muscle formation. For example, IL-6 has been proposed as one of the effectors of the promyogenic mechanism of a crosstalk between p38 MARK and NF-KB signaling in $\mathrm{C} 2 \mathrm{C} 12$ cells [70]. However, combination of TNF with other inflammatory cytokines such as IL1- $\beta$ or IL-6 had no effect on skeletal muscle gene expression [60]. Similarly, human IL- $1 \alpha$ and $1 \beta$ combined with TNF- $\alpha$ had no effect on the regulation of protein balance in skeletal muscle [71]. Although interferon- $\gamma$ (INF- $\gamma$ ) also had no effect on $\mathrm{C} 2 \mathrm{C} 12$ myotubes, when differentiated myotubes were treated with a combination of TNF and INF- $\gamma$, a significant reduction was seen in both $\mathrm{MyoD}$ and myosin heavy chain (MyHC, a muscle differentiation marker) protein expression [60]. Thus, the synergistic effects of cytokines may
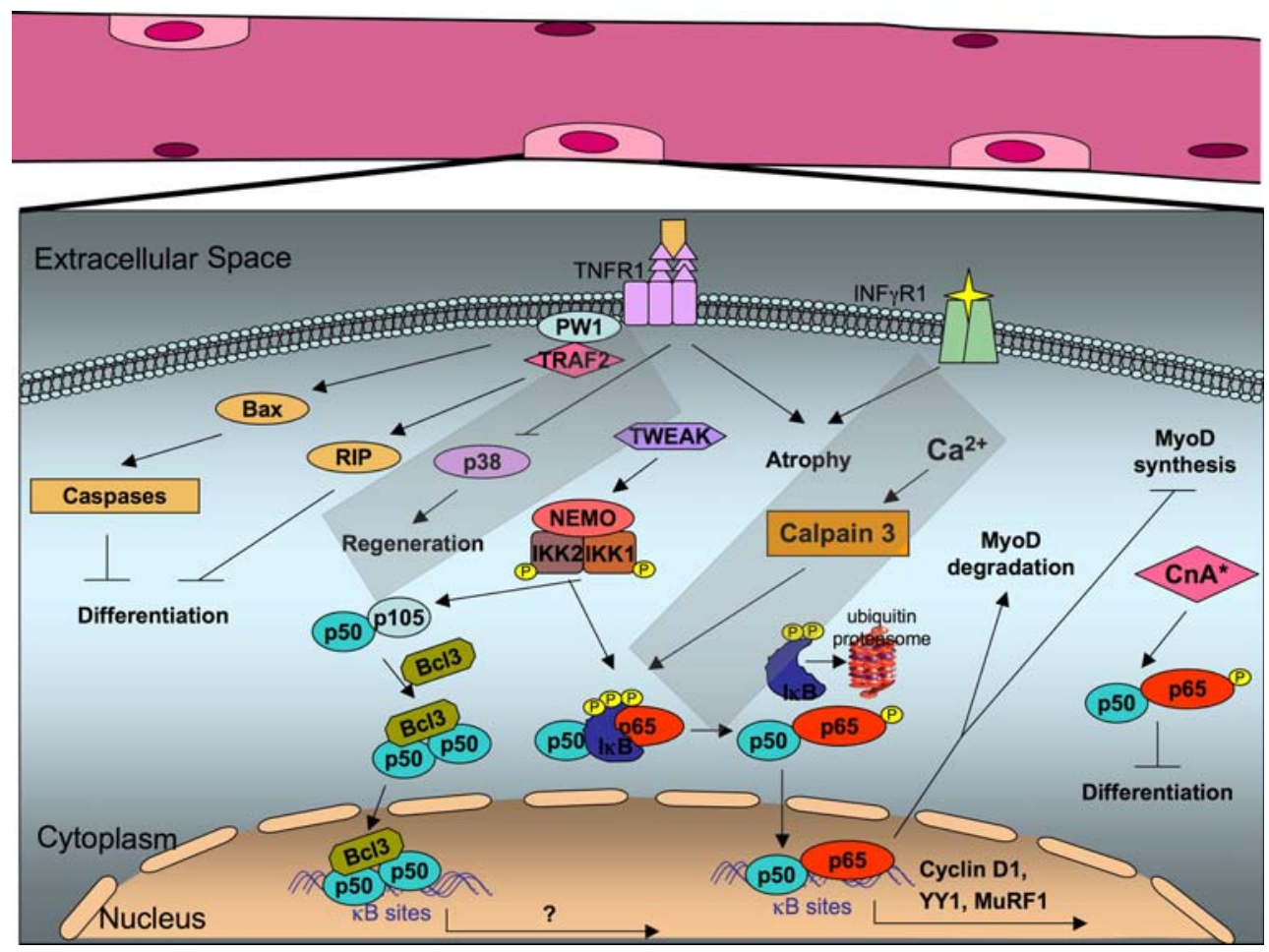

Fig. 2 NF- $\kappa B$ pathway in skeletal muscles. NF- $k B$ binds on $\kappa B$ sites of the cyclin D1 promoter and regulates its transcription. Moreover, the $\mathrm{p} 65 / \mathrm{p} 50$ heterodimer complex binds to the transcriptional repressor YY1, resulting in inhibition of skeletal myogenesis. TNF- $\alpha$ and TWEAK activation regulates MyoD1 expression through a p65/p50 complex. In response to TNF signaling, PW1 associates with TRAF2, induces Bax translocation in mitochondria, and through activation of caspases, leads to inhibition of muscle differentiation. TNF- $\alpha$ signaling is important for the activation of satellite cells during muscle regeneration, through the MAP kinase p38. Synergistic effects of TNF and INF- $\gamma$ result in muscle atrophy. Stable expression of constitutively active $\mathrm{CnA}$ in $\mathrm{C} 2 \mathrm{C} 12$ cells induces NF- $\mathrm{KB}$ activation in a TNF- $\alpha$-independent mechanism. Intracellular calcium in muscle cells activates calpain 3 , which induces $\operatorname{I} \kappa \mathrm{B} \alpha$ degradation, leading to $\mathrm{NF}-\kappa \mathrm{B}$ activation and translocation into the nucleus, where it regulates expression of survival genes. Upon denervation-induced atrophy, NF$\mathrm{KB}$ binds on the promoter of MuRF1. Upon unloaded-induced atrophy, complexes comprising of p50 and Bcl-3 subunits are activated and translocate into the nucleus to regulate transcription of target genes. MuRF1 Murine ring finger-1, YY1 YinYang1, PW1/Peg3 paternally expressed 3, TWEAK TNF weak inducer of apoptosis, CnA activated form of calcineurin A, Bax Bcl-2-associated X protein, TRAF2 TNF-receptor-associated factor 2 , RIP receptor-interacting protein, TNFR 1 tumor necrosis factor receptor $1, I N F-\gamma R 1$ interferon$\gamma$ receptor $1, I K K$ I $\mathrm{kB}$ kinase, $N E M O$ NF- $\mathrm{KB}$ essential modulator 
have a higher impact on muscle function, implying that activation of NF-KB via a single cytokine may be insufficient to mediate profound differences in myogenic expression.

In an attempt to link NF- $\mathrm{KB}$ with other important signaling molecules, cell culture experiments in $\mathrm{C} 2 \mathrm{C} 12$ cells showed that stable expression of constitutively active calcineurin $\mathrm{A}(\mathrm{CnA})$ induced NF-kB activation (Fig. 2). Surprisingly, CnA-induced NF- $\mathrm{kB}$ activation interfered with terminal muscle differentiation, without the involvement of TNF- $\alpha$ [72] suggesting that in skeletal muscles non-cytokine-related cascades can also activate NF-KB. Calpain 3-dependent activation of NF- $\mathrm{KB}$ constitutes another example of TNF- $\alpha$-independent regulation [3], presumably by accumulation of IKB $\alpha$ in the sarcoplasm due to calpain 3-dependent degradation. Excessive I $\mathrm{K} B \alpha$ traps NF- $\mathrm{kB}$ in the cytoplasm, blocks NF- $\mathrm{kB}$ translocation to the nucleus, halts transcriptional expression of survival genes and therefore sensitizes the muscle cells to apoptosis [3] (Fig. 2).

In summary, myogenic cell lines respond to proinflammatory cytokines by engaging the NF- $\mathrm{KB}$ pathway, which acts as a mitogen in muscle proliferation and as a negative regulator in late differentiation. So far, only few components of the pathway that regulate muscle function are known (highlighted in Fig. 2) where most of them are extrapolated from cell culture experiments. Moreover, the exact role of the NF- $\mathrm{kB}$ signaling pathway during skeletal muscle development depends on the state of the cell, such that skeletal muscles under physiological conditions have lower NF-KB activity with different transcriptional profiles compared to stressed muscles. The various transcriptional mechanisms of NF-KB in skeletal muscle, in combination with the synergistic effects of other signals such as p38, calcineurin, or calpain 3 emphasize the necessity for further studies to better understand the mechanisms behind the diverse roles of NF- $\mathrm{KB}$ and to distinguish its function in physiological and muscle disease conditions.

\section{Muscle diseases and NF- $\kappa$ B}

The potential role of NF- $\mathrm{KB}$ in skeletal muscle pathology has received particular attention, since any severe functional dysregulation of skeletal muscle leads to weakness and progressive tissue death. The most common pathology associated with muscle disease is muscle atrophy which causes a decrease in muscle mass. The etiological basis of skeletal muscle atrophy includes cancer, AIDS, and heart failure [73], but regardless of the cause, it is characterized by a decrease in total protein, fiber diameter, and force production [74]. Different techniques have been developed in animal models to mimic the effects of muscle atrophy and to dissect the molecular mechanisms that underlie this pathological condition. Using immobilization studies in rats [75] and mice [45], direct muscle injections of either cytokines (TNF, INF- $\gamma$ ) or cancer cells [60], as well as denervation of the sciatic nerve to induce muscle wasting $[4,5]$ (Table 1), researchers have shown that NF-kB levels are strongly upregulated upon muscle atrophy. Indeed, attempts to inhibit the NF- $\mathrm{KB}$ pathway in several atrophy models prevented muscle degeneration and myofiber death $[4,5,45,75]$.

Sarcopenia is another form of muscle decline, a normal consequence of aging that leads to a gradual inability to maintain skeletal muscle function and mass [74]. In one study, NF-kB protein concentrations were found to be fourfold higher in elderly human muscles compared to those of young people [76]. However, to date there are no documented studies that investigate the exact mechanism by which NF-KB acts in aging muscle.

Muscular dystrophies are inherited muscle diseases, of which Duchenne muscular dystrophy (DMD) is the most common. DMD is a X-linked recessive progressive musclewasting disorder that results from the absence of the dystrophin sarcomeric protein [77]. The most widely used animal model for DMD is the mdx mouse, arising from a spontaneous mutation in the dystrophin gene. Homozygous animals are viable but present histological lesions similar to

Table 1 Muscle diseases and NF-KB

\begin{tabular}{lll}
\hline Disease & Model & References \\
\hline Humans & & \\
Muscular atrophy & & \\
Muscle sarcopenia & & {$[76]$} \\
Muscular dystrophies & & {$[81]$} \\
Duchenne muscular dystrophy & & {$[3]$} \\
Limb-girdle muscular dystrophy type 2A & & \\
Inflammatory myopathies & & {$[81]$} \\
Dermatomyositis & & {$[81]$} \\
Polymyositis & & {$[86]$} \\
Inclusion body myositis & & \\
& & \\
Animal models & & \\
Muscular atrophy & Mice & {$[4,5]$} \\
Denervation (atrophy due to & & \\
nervous dysfunction) & Rats, & {$[45,75]$} \\
Unloading (disuse atrophy) & mice & \\
& Mice & {$[4,60]$} \\
Cancer cachexia & Mice & {$[60]$} \\
TNF/INF- $\gamma$ muscular injections & & \\
Muscular dystrophies & Mice \\
Mdx model & Mice \\
Double mdx/utr model & Mice \\
Toxin injection (regeneration model) & {$[83]$} \\
Freeze injury (regeneration model) & Mice & {$[103]$} \\
\hline
\end{tabular}


the ones observed in human muscular dystrophy [78]. Dystrophy is characterized by muscle membrane damage, chronic inflammation, necrosis, and severe muscle degeneration [77]. With time, repetitive rounds of damage and repair in dystrophic muscles eventually exhaust the regenerative capacity of the tissue and lead to persistent inflammation [79]. In particular, NF-kB-related cytokines, such as TNF- $\alpha$, were upregulated in dystrophic muscles from DMD patients [80]. Moreover, cytoplasmic localization of the p65 subunit of the NF- $\mathrm{KB}$ heterodimer is a hallmark of regenerating muscle fibers in DMD patients [81]. Consistently, dystrophic muscle cells have increased susceptibility to oxidative stress as was shown in muscles from both DMD patients and mdx mice. These observations suggest that products of oxidative stress might be involved in the dystrophic process, triggering an inflammatory response [82] and leading to NF- $\mathrm{KB}$ activation. Interestingly, recent studies [83] found that IKK/NF- $\mathrm{kB}$ signaling is persistently elevated in immune cells and regenerating muscle fibers in mdx mice as well as patients, supporting a strong association of NF- $\mathrm{KB}$ activation with the dystrophic phenotype. Indeed, another type of muscular dystrophy, the limb-girdle muscular dystrophy type 2A (LGMD2A) has also been affiliated with the NF-KB pathway. LGMD is characterized by progressive symmetrical atrophy and weakness at the proximal limb, scapular pelvic girdle, and trunk muscles, without affecting facial muscles [84]. LGMD2A correlates with calpain 3 deficiency that leads to myonuclear apoptosis through a mechanism mentioned previously in this review (Fig. 2). According to this model, calpain 3 controls $\mathrm{I} K \mathrm{~B} \alpha$ turnover and indirectly regulates NF- $k B$-dependent expression of survival genes, suggesting an unexpected anti-apoptotic role of NF-KB in LGMD2A.

Inflammatory myopathies are another heterogeneous group of muscle disorders that are defined by muscle weakness and high infiltration of inflammatory cells in muscle tissues [77]. Autoimmune inflammatory myopathies can be classified into polymyosisitis (PM), dermatomyositis, and sporadic inclusion-body myositis (s-IBM), according to differences in clinical and histopathological features [85]. Strong expression of pro-inflammatory cytokines has been reported in all inflammatory myopathies with higher levels for TNF- $\alpha$ and IL-1 [85]. In PM patients, NF-KB immunoreactivity has been observed in all regenerating fibers and in $30-40 \%$ of fibers with features of necrosis and phagocytosis [81]. Furthermore, muscle biopsies of eight IBM patients were immunostained with specific antibodies against p50 and p65 displayed approximately $70 \%$ of IBM vacuolated muscle fibers with strong local accumulation of both p50 and p65 subunits [86]. The differential distributions of NF-KB subunits in necrotic fibers, neuromuscular junctions, and regenerating areas suggest different roles of each subunit in muscle pathology.
A summary of the different human or animal model diseases and their connection with the NF- $\mathrm{KB}$ signaling pathway is shown in Table 1. NF- $\mathrm{KB}$ does not only play a role in regulating myogenesis as suggested by myogenic cultures, but it is likely to modulate immune responses, muscle damage, and repair in DMD as well as in other muscle disorders. The survival effect of NF-kB in LGMD2A muscles compared with its rather negative contribution in the other dystrophinopathies indicates that this complicated area of biology has only begun to unfold.

\section{Genetic models of NF- $\mathrm{BB}$ signaling in skeletal muscles}

Over the last years, different laboratories worked on genetically manipulated transgenic and knockout mice that were designed to interfere with one or more components of the NF-KB pathway to mimic the diverse aspects of NF- KB signaling in muscle pathophysiology. Substantial effort [48, $50,55]$ has focused on the role of the TNF- $\alpha$ signaling pathway during muscle regeneration. However, the results are contradictory as the effects vary among the different animal models (Table 2). More specifically, abnormal regeneration, excess inflammation, and calcification were observed in the regenerating soleus muscle of TNF- $\alpha$ receptor double knockouts $\mathrm{p} 55^{-/-} / \mathrm{p} 75^{-/}$[50], due to impaired p38 activation [48]. On the other hand, regeneration studies on $\mathrm{TNF} \alpha^{-1-}$ and TNF- $\alpha$ and lymphotoxinalpha (LT- $\alpha$, a TNF- $\alpha$ homologue, also called TNF-beta), double knockout mice $\left(\mathrm{TNF}^{-/-} / \mathrm{LT} \alpha^{-/-}\right)$, revealed no major differences in the regeneration capacity [55]. Finally, histopathological measurements on $\mathrm{TNF} \alpha^{-/-} / \mathrm{mdx}$ animals showed opposite results in diaphragm and quadriceps muscles [87]. Although various injury models were used in the above studies, their variable regeneration effects suggest that TNF signaling might be under additional regulation than just NF- $\mathrm{KB}$ activation in muscle reconstitution and therefore, it will be important to analyze mouse models which affect downstream targets of TNF.

Two transgenic mouse models have been generated in which NF-KB is either activated or inhibited selectively in skeletal muscle by targeting the IKK2/IKK $\beta$ subunit of the IKK complex. In MIKK mice, the muscle creatine kinase (MCK) promoter was used to drive the expression of constitutively active IKK $\beta$ (SS177/181EE mutant), while in MISR mice the same promoter drove expression of the dominant inhibitory IKB $\alpha$ (SS32/36AA mutant) [4]. MIKK mice exhibited a severe muscle-wasting phenotype in both limb and trunk muscles and a relative reduction in muscle mass increasing with age. MISR mice showed decreased muscle wasting both after denervation-induced atrophy and after cancer cachexia [4]. These mouse models provided the 
Table 2 Genetic models to study NF-kB function in skeletal muscle development and disease

\begin{tabular}{|c|c|c|}
\hline Mouse models & Reported muscle effect & References \\
\hline $\mathrm{p} 55^{-/-} / \mathrm{p} 75^{-/-}$ & Abnormal soleus regeneration (excess of inflammation, calcification) & {$[48,50]$} \\
\hline $\mathrm{TNF} \alpha^{-1-}$ mice & No difference in muscle regeneration & {$[55]$} \\
\hline $\mathrm{TNF} \alpha^{-1-} / \mathrm{LT} \alpha^{-/-}$mice & No difference in muscle regeneration & {$[55]$} \\
\hline $\mathrm{TNF} \alpha^{-1-} / \mathrm{mdx}$ & Different effects on diaphragm and quadriceps & {$[87]$} \\
\hline $\mathrm{TRAF}^{-/-}$mice & Born with decreased muscle mass & {$[63]$} \\
\hline MISR mice (MCK-DNIkB $\alpha$ SS32/36AA) & Reduced muscle loss under atrophy conditions & {$[4]$} \\
\hline MIKK mice (MCK-IKK $\beta$ SS177/181EE) & Muscle atrophy & {$[4]$} \\
\hline $\mathrm{IKK}^{\mathrm{mko}}\left(\mathrm{MCK} \mathrm{Cre} / \mathrm{IKK} 2^{\mathrm{fl} / \mathrm{fl}}\right)$ & $\begin{array}{l}\text { Shifted muscle fiber distribution, improved muscle force, } \\
\text { protection against muscle atrophy, improved regeneration }\end{array}$ & [5] \\
\hline $\mathrm{mIGF} 1 / \mathrm{IKK} 2^{\mathrm{mko}}$ & Enhanced muscle atrophy protection & {$[5]$} \\
\hline $\mathrm{MLC}$ Cre/IKK $2^{\mathrm{fl} / \mathrm{fl}}$ & Promotes regeneration & [83] \\
\hline $\mathrm{Mdx} / \mathrm{MLC} \mathrm{Cre} / \mathrm{IKK} 2^{\mathrm{fl} / \mathrm{fl}}$ & Increased muscle progenitor cells during regeneration & [83] \\
\hline Mdx/Lys Cre/IKK2 $2^{\mathrm{fl} / \mathrm{fl}}$ & Reduces inflammation in dystrophic muscle & [83] \\
\hline $\mathrm{Mdx} / \mathrm{p} 50^{-/-}$ & No influence in mdx pathology & [83] \\
\hline $\mathrm{Mdx} / \mathrm{p} 65^{+/-}$mice & Rescues mdx pathology & {$[83]$} \\
\hline $\mathrm{Bcl}^{-/-}$mice & Inhibits muscle atrophy (both fast and slow fibers affected) & {$[45]$} \\
\hline $\mathrm{p} 50^{-/-}$mice & Inhibits muscle atrophy (only fast fibers affected) & {$[45]$} \\
\hline $\mathrm{c}-\mathrm{Rel}^{-/-}$mice & No influence during atrophy & {$[44]$} \\
\hline
\end{tabular}

first evidence that muscle-specific activation of IKK $\beta / N F-\kappa B$ pathway is sufficient to induce atrophy [4].

Further information about the role of NF- $\mathrm{KB}$ in muscle pathophysiology came through analysis of knockout mice that lacked single components of the signaling cascade. The first NF- $\mathrm{KB}$ muscle specific knockout mouse was generated by muscle-specific creatine kinase-driven Cre deletion (MCK-Cre) of the IKK2 subunit [5]. In these mice, also

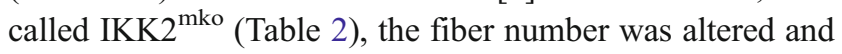
muscle strength as well as physical performance was improved, arguing that manipulations of the IKK activity affect skeletal muscle physiology. Moreover, denervationinduced atrophy in IKK $2^{\text {mko }}$ mice was minimal and in addition the shift from a mixed to a faster fiber phenotype, which is typically observed during muscle atrophy, was abolished [5]. Consequently, muscle force in IKK2 ${ }^{\text {mko }}$ denervated muscles remained high, most likely due to a synergistic effect of maintaining both muscle mass and fiber integrity. Indeed, IKK2 muscle depletion stabilized muscle homeostasis both by promoting protein synthesis and attenuating protein degradation via the ubiquitinaseligase molecule muscle RING finger 1 (MuRF1) [5]. A working model of NF- $\mathrm{BB}$ inhibition was proposed, in which IKK2 depletion restabilizes a new ratio of protein/ degradation in response to the changes caused by muscle atrophy [5] without affecting insulin and glucose homeostasis [88]. Furthermore, it was demonstrated that the combination of IGF1 supplementation with NF- $\mathrm{KB}$ inhibition further reduces the pathological symptoms of muscle atrophy [5], implying that the NF-KB pathway can interfere with other signals during muscle homeostasis.
Using cardiotoxin (CDX) injection as a model for muscle injury [5], it was demonstrated that NF-кB inhibition reduced inflammation and enhanced myoblast contribution after local muscle damage, providing evidence that the muscle regeneration process in IKK $2^{\text {mko }}$ animals was accelerated. It is very likely that fusion and hypertrophic growth have been enhanced through disruption of NF-KB signaling [5]. Consistently, it was recently shown [83] that deletion of IKK2 subunit under the control of the muscle light chain promoter (MLC), in response to acute injury can also lead to increased regeneration. In the context of DMD, in $\mathrm{mdx} / \mathrm{MLC} \mathrm{Cre/IKK} 2^{\mathrm{fl} / \mathrm{fl}}$ muscles the increased number of MyoD positive and neonatal MyHC cells [83] was indicative for the formation of new fibers during muscle reconstitution. Muscle regeneration, which occurs in response to injury, involves inflammation and cytokine stimulation that is produced by the infiltrating cells [79]. IKK $2^{\text {mko }}$ mice seem to accelerate regeneration in part by limiting the inflammation process [5]. Indeed, myeloidspecific lysozyme-driven Cre deletion (Lys-Cre) of the IKK2 subunit in mdx mice ( $\mathrm{mdx} / \mathrm{Lys} \mathrm{Cre} / \mathrm{IKK} 2^{\mathrm{fl} / \mathrm{fl}}$ ) revealed that muscle pathology was noticeably improved [83].

Further studies have focused the role on specific NF- $\kappa \mathrm{B}$ subunits. Since $\mathrm{p} 65^{-/-}$mice are not viable [10], the regeneration properties of $\mathrm{p} 65^{+/-}$heterozygous mice were analyzed. Heterozygous deletion of p65, but not p50, promotes regenerative myogenesis in $\mathrm{mdx}$ mice [83], suggesting that the dystrophic pathology is selectively regulated by the p65 subunit of the NF-kB dimer. These mouse models were extremely useful, as they provided a direct link between NF- $\mathrm{kB}$-controlled activation and mus- 
cle injury. Based on this evidence, it was suggested that the role of NF-kB activity, which is present in dystrophic patients, is very likely to arise from both immune cells and muscle fibers.

From the muscle-specific effects of different genetic mouse models, it is clear that tissue-specific manipulations of NF- $\mathrm{KB}$ signaling provide valuable information in dissecting more accurately the NF-KB pathway in muscle physiology and disease. The question that arises is whether our current knowledge of NF-kB signaling in skeletal muscle is sufficient to initiate pharmacological interventions.

\section{Pharmacological manipulation of the NF-KB pathway in skeletal muscle disease models}

The NF- $\mathrm{KB}$ signaling pathway has provided a target for pharmacological invention and over 750 inhibitors of this pathway have been identified, including a variety of natural and synthetic molecules [89]. Many therapeutic trials have been undertaken using NF-kB-dependent modulators (Table 2) with the purpose of ameliorating the pathology of muscular dystrophies as well as other muscle diseases.

The approaches that have been attempted in animal models include components that interfere with TNF activity, such as Remicade (an antibody) or Enbrel (a soluble TNF receptor) $[90,91]$, aiming to block the acute inflammatory cell response during whole muscle graft experiments in mice. Enbrel appeared to be more effective than Remicade in blocking TNF- $\alpha$ function and reducing the inflammation response, but both drugs were able to reduce the breakdown of dystrophic muscles in treated mdx mice [91]. Conversely, treatments that induce TNF activity, such as direct TNF gene transfer by electroporation into mouse muscle, inhibited skeletal muscle regeneration in a model of freeze injury [92]. Thus, TNF treatment might be a controversial target for immunotherapy for DMD, since the effects are not consistent.

In 1999, Thallor et al. suggested that systemic treatment with curcumin, which acts as an NF-kB inhibitor, led to faster restoration of normal muscle architecture as well as increased expression of biochemical markers associated with muscle regeneration [93], when administered after local muscle injury. Recently, another group investigated the effects of NF-KB blocking by pyrrolidine dithiocarbamate (PDTC), a synthetic antioxidant that acts as another $\mathrm{NF}-\mathrm{KB}$ inhibitor in $\mathrm{mdx}$ mice. This treatment increased forelimb strength, decreased fatigue percentage, reduced muscle necrosis, and enhanced muscle regeneration in $\mathrm{mdx}$ mice [93]. However, it is well known that curcumin induces several other transcription factors, such as activating protein 1 (AP-1) [94] or nuclear respiratory factor 2 (Nrf2) [95] and PDTC also induces Nrf2 [96]. Therefore, although curcu- min and PDTC might produce beneficial effects in skeletal muscles, it is likely that these effects might be the result of additional pathways than only NF-KB activity.

Even more recent evidence showed that pharmacological inhibition at the level of the IKK subunits by using the cellpermeable NEMO-binding domain (NBD) peptide, during the pre-necrotic phase in $\mathrm{mdx}$ mice, was sufficient to decrease macrophage infiltration and sarcoplasmic membrane lysis [83]. Moreover, if treatment was pursued during the post-necrotic phase, in addition to the high reduction in immune cell infiltration, the number of newly forming fibers was increased and the electrophysiological properties of the affected muscles were improved [83]. Therefore, pharmacological blockade of NF- $\mathrm{KB}$ produces beneficial effects on functional, biochemical, and morphological parameters of dystrophic muscles and targeting the IKK/ NF-KB pathway could improve the secondary pathology of DMD.

In the context of muscle atrophy, it was shown that treatment with high dosages of sodium salicylate, a component that has been shown to inhibit NF-kB [97], the atrophy phenotype of the MIKK mice was diminished [4]. However, sodium salicylate has a range of other targets besides NF-kB $[4,98]$, and the high doses that are required for sufficient reversal of the atrophy phenotype might give other side effects.

Finally, two other pharmacological components, named pentoxifylline and thalidomide, which work as TNF-a blockers, have been evaluated in clinical trials of cachexia [99, 100]. Thalidomide has shown promising results in patients with cancer cachexia [100], while pentoxifylline was evaluated in cancer cachexia patients without demonstrating any benefit in a small group of patients [99]. In addition, pentoxifylline is used in an on-going (phase II) clinical trial against the pathology of DMD [104] (Table 3). However, pentoxifylline acts also as a phosphodiesterase 4 inhibitor, increasing cAMP and stimulating PKA activity [99], therefore the outcome of the pentoxifylline treatment cannot be attributed exclusively to TNF- $\alpha$ inhibition.

The different pharmacological approaches that interfere with the NF-KB signaling pathway (summarized in Table 3) constitute attractive therapies for the dystrophic phenotype in animal models; however, these applications cannot yet be directly applied to human clinical trials. Various precautions must be taken before these agents are used to manipulate NF-KB signaling in different muscle conditions since (a) there is not enough proof about the specificity of the existing molecules, (b) long pharmacological inhibition of NF- $\mathrm{KB}$ signaling raises serious concerns about the effects on the patient's immune system, and (c) different muscle conditions might require different manipulations of NF-KB signaling in a more cell-typespecific way. 
Table 3 NF-kB pharmacological models that interfere with muscular pathology

\begin{tabular}{|c|c|c|c|c|}
\hline Pharmacological components & Way of action & Reported muscle effect & Animal & References \\
\hline NBD peptide & NEMO-specific inhibitor dystrophic & Improving pathology & Mice & [83] \\
\hline Salicylate & $\begin{array}{l}\text { IKK } \beta \text { inhibitor but also has a range } \\
\text { of other targets }\end{array}$ & Severe reduction of muscle atrophy & Mice & {$[4]$} \\
\hline Remicade & Silencing TNF- $\alpha$ activity & $\begin{array}{l}\text { Reduced breakdown of dystrophic } \\
\text { muscle }\end{array}$ & Mice & {$[90,91]$} \\
\hline Enbrel & Silencing TNF- $\alpha$ activity & Reduced inflammation & Mice & [91] \\
\hline Curcumin & $\begin{array}{l}\mathrm{NF}-\mathrm{kB} \text { inhibitor also induces AP-1 } \\
\text { and Nrf2 }\end{array}$ & Stimulates muscle regeneration & Mice & [102] \\
\hline $\begin{array}{l}\text { Synthetic antioxidant also induces } \\
\text { Nrf2 pyrrolidine dithiocarbamate } \\
\text { (PDTC) }\end{array}$ & NF- $\mathrm{kB}$ inhibitor & $\begin{array}{l}\text { Ameliorates the dystrophic } \\
\text { phenotype }\end{array}$ & Mice & [93] \\
\hline $\operatorname{mTNF} \alpha$ gene transfer & Induce TNF activity & $\begin{array}{l}\text { Induces cachexia, inhibits muscle } \\
\text { regeneration }\end{array}$ & Mice & {$[92]$} \\
\hline Thalidomide & Inhibitor of TNF- $\alpha$ synthesis & $\begin{array}{l}\text { Attenuation of loss weight and } \\
\text { lean body mass in patients with } \\
\text { pancreatic cancer }\end{array}$ & Humans & {$[100]$} \\
\hline Pentoxifylline & $\begin{array}{l}\text { TNF- } \alpha \text { inhibitor, also a PDE4 inhibitor } \\
\text { (increasing cAMP and stimulating } \\
\text { PKA activity) }\end{array}$ & $\begin{array}{l}\text { No benefits } \\
\text { On-going clinical trial in DMD, } \\
\text { phase II }\end{array}$ & $\begin{array}{l}\text { Humans } \\
\text { Humans }\end{array}$ & $\begin{array}{l}{[99]} \\
{[104]}\end{array}$ \\
\hline
\end{tabular}

$A P-1$ Activating protein $1, N r f 2$ nuclear respiratory factor 2, PDE4 phosphodiesterase 4

\section{Conclusions}

It is now becoming clear that in addition to its recognized role as a key regulator of immune and inflammatory responses, NF-kB has recently emerged as a decisive factor in the muscle cell's response to aging and disease. Considering the past and current literature on the role of NF- $\kappa \mathrm{B}$ in skeletal muscle physiology and disease, a pleitropic nature of this transcription factor becomes evident, as NF- $\mathrm{KB}$ activity seems to directly regulate MyoD, cyclin D1, and probably other molecules such as MuRF1 upon atrophy conditions. Although this makes NF$\mathrm{KB}$ the subject of inquiry for many laboratories with diverse interests and we continue to gain insights from parallel efforts, it is fair to say that many more questions remain to be answered. For example, which are the exact NF-кB components specifically in muscle cells? Are there only p65, p50, and $\mathrm{Bcl} 3$ and how they act differently under different pathological conditions? Which are the genes that $\mathrm{NF}-\kappa \mathrm{B}$ regulates in skeletal muscles? How are they regulated in the transcriptional, post-transcriptional, translational, or even a post-translational level? Most of the existing literature is only referring to the canonical NF- $\mathrm{KB}$ pathway. Studies remain to be designed that investigate the possibility of alternative pathways or IKK-independent functions in skeletal muscles, which might explain why the NF- $\kappa$ B pathway plays the villain in some muscle diseases, such as DMD, while it is beneficial in others such as LGMD2A.
The growing appreciation of the role of NF- $\mathrm{KB}$ in human diseases raises additional questions. For example, how do the different cell types in the muscle tissue coordinate their NF- $\mathrm{kB}$ functions? Muscle regeneration is considered successful when inflammatory cell infiltration after injury is followed by muscle repair and growth. This process involves activation, proliferation, and terminal differentiation of satellite cells, followed by the ability of new axons to reach the myofibers [79]. Therefore, it is essential to understand in depth the relationship between the different cells, as well as the contribution of NF- $\mathrm{kB}$ interactions with other muscle-specific regulators. We have yet to be able to distinguish the effects of NF-KB in muscle cells from other cell types that are involved during the muscle healing process. Given the fact that NF-KB subunits are expressed in many different cell types under various muscle conditions, it might be not surprising that the number of functions in which an NF- $\mathrm{B}$ may be involved will vary depending upon the muscle state in which it is found. For example under muscle regeneration conditions, TWEAK (a TNF-like inducer) is secreted from the invading macrophages and can bind its receptor expressed in muscle cells, promoting proliferation and activation of myoblasts, which can in turn contribute to an inflammatory response by producing additional chemoattractants [101]. No doubt that a better understanding of the NF- $\mathrm{KB}$ signaling cascades that are involved in specific muscle processes will be important for the development of new generations of drugs with higher efficiency, less side effects, and lower cost. 
Acknowledgments We are grateful to Arianna Nenci, Theodoros Tsetsenis, and Paschalis Kratsios for critical comments and helpful discussions. Our apology for any relevant work that was not cited here because of space constrains. This work was supported by a grant from MYORES European Muscle Development Network.

Open Access This article is distributed under the terms of the Creative Commons Attribution Noncommercial License which permits any noncommercial use, distribution, and reproduction in any medium, provided the original author(s) and source are credited.

\section{References}

1. Li Q, Verma IM (2002) NF-kappaB regulation in the immune system. Nat Rev Immunol 2(10):725-734

2. Perkins ND (2004) NF-kappaB: tumor promoter or suppressor. Trends Cell Biol 14(2):64-69

3. Baghdiguian S et al (1999) Calpain 3 deficiency is associated with myonuclear apoptosis and profound perturbation of the IkappaB alpha/NF-kappaB pathway in limb-girdle muscular dystrophy type 2A. Nat Med 5(5):503-511

4. Cai D et al (2004) IKKbeta/NF-kappaB activation causes severe muscle wasting in mice. Cell 119(2):285-298

5. Mourkioti $F$ et al (2006) Targeted ablation of IKK2 improves skeletal muscle strength, maintains mass, and promotes regeneration. J Clin Invest 116(11):2945-2954

6. Nenci A et al (2006) Skin lesion development in a mouse model of incontinentia pigmenti is triggered by NEMO deficiency in epidermal keratinocytes and requires TNF signaling. Hum Mol Genet 15(4):531-542

7. van Loo $G$ et al (2006) Inhibition of transcription factor NFkappaB in the central nervous system ameliorates autoimmune encephalomyelitis in mice. Nat Immunol 7(9):954-961

8. Gareus R et al (2007) Normal epidermal differentiation but impaired skin-barrier formation upon keratinocyte-restricted IKK1 ablation. Nat Cell Biol 9(4):461-469

9. Ventura JJ et al (2007) p38alpha MAP kinase is essential in lung stem and progenitor cell proliferation and differentiation. Nat Genet 39(6):750-758

10. Ghosh S, May MJ, Kopp EB (1998) NF-kappa B and Rel proteins: evolutionarily conserved mediators of immune responses. Annu Rev Immunol 16:225-260

11. Hayden MS, Ghosh S (2004) Signaling to NF-kappaB. Genes Dev 18(18):2195-2224

12. Hacker H, Karin M (2006) Regulation and function of IKK and IKK-related kinases. Sci STKE 2006(357):re13

13. Schmitz ML, Baeuerle PA (1991) The p65 subunit is responsible for the strong transcription activating potential of NF-kappa B. EMBO J 10(12):3805-3817

14. Betts JC, Nabel GJ (1996) Differential regulation of NFkappaB2(p100) processing and control by amino-terminal sequences. Mol Cell Biol 16(11):6363-6371

15. Fan CM, Maniatis T (1991) Generation of p50 subunit of NFkappa B by processing of p105 through an ATP-dependent pathway. Nature 354(6352):395-398

16. Perkins ND (2007) Integrating cell-signalling pathways with NFkappaB and IKK function. Nat Rev Mol Cell Biol 8(1):49-62

17. Birbach A et al (2002) Signaling molecules of the NF-kappa B pathway shuttle constitutively between cytoplasm and nucleus. J Biol Chem 277(13):10842-10851

18. Dechend R et al (1999) The Bcl-3 oncoprotein acts as a bridging factor between NF-kappaB/Rel and nuclear co-regulators. Oncogene 18(22):3316-3323
19. Ghosh S, Karin M (2002) Missing pieces in the NF-kappaB puzzle. Cell 109(Suppl):S81-S96

20. Zandi E et al (1997) The IkappaB kinase complex (IKK) contains two kinase subunits, IKKalpha and IKKbeta, necessary for IkappaB phosphorylation and NF-kappaB activation. Cell 91 (2):243-252

21. Yamaoka S et al (1998) Complementation cloning of NEMO, a component of the IkappaB kinase complex essential for NFkappaB activation. Cell 93(7):1231-1240

22. Chen ZJ (2005) Ubiquitin signalling in the NF-kappaB pathway. Nat Cell Biol 7(8):758-765

23. Bonizzi G, Karin M (2004) The two NF-kappaB activation pathways and their role in innate and adaptive immunity. Trends Immunol 25(6):280-288

24. Anest V et al (2003) A nucleosomal function for IkappaB kinasealpha in NF-kappaB-dependent gene expression. Nature 423 (6940):659-663

25. Yamamoto $\mathrm{Y}$ et al (2003) Histone H3 phosphorylation by IKKalpha is critical for cytokine-induced gene expression. Nature 423(6940):655-659

26. Park KJ et al (2005) Formation of an IKKalpha-dependent transcription complex is required for estrogen receptor-mediated gene activation. Mol Cell 18(1):71-82

27. Albanese $\mathrm{C}$ et al (2003) IKKalpha regulates mitogenic signaling through transcriptional induction of cyclin D1 via Tcf. Mol Biol Cell 14(2):585-599

28. Kwak YT et al (2005) IkappaB kinase alpha regulates subcellular distribution and turnover of cyclin D1 by phosphorylation. J Biol Chem 280(40):33945-33952

29. Hu Y et al (2001) IKKalpha controls formation of the epidermis independently of NF-kappaB. Nature 410(6829):710-714

30. Ohazama A et al (2004) A dual role for Ikk alpha in tooth development. Dev Cell 6(2):219-227

31. $\mathrm{Hu} \mathrm{MC}$ et al (2004) IkappaB kinase promotes tumorigenesis through inhibition of forkhead FOXO3a. Cell 117(2):225-237

32. Gringhuis SI et al (2005) Convergent actions of I kappa B kinase beta and protein kinase $\mathrm{C}$ delta modulate mRNA stability through phosphorylation of 14-3-3 beta complexed with tristetraprolin. Mol Cell Biol 25(15):6454-6463

33. Wu ZH et al (2006) Molecular linkage between the kinase ATM and NF-kappaB signaling in response to genotoxic stimuli. Science 311(5764):1141-1146

34. O'Neill LA, Bowie AG (2007) The family of five: TIR-domaincontaining adaptors in Toll-like receptor signalling. Nat Rev Immunol 7(5):353-364

35. Tanaka M et al (1999) Embryonic lethality, liver degeneration, and impaired NF-kappa B activation in IKK-beta-deficient mice. Immunity 10(4):421-429

36. Luedde T et al (2007) Deletion of NEMO/IKKgamma in liver parenchymal cells causes steatohepatitis and hepatocellular carcinoma. Cancer Cell 11(2):119-132

37. Kaltschmidt C et al (1994) Constitutive NF-kappa B activity in neurons. Mol Cell Biol 14(6):3981-3992

38. Mattson MP, Camandola S (2001) NF-kappaB in neuronal plasticity and neurodegenerative disorders. J Clin Invest 107(3): 247-254

39. Kaufman CK, Fuchs E (2000) It's got you covered. NF-kappaB in the epidermis. J Cell Biol 149(5):999-1004

40. Pasparakis $M$ et al (2002) TNF-mediated inflammatory skin disease in mice with epidermis-specific deletion of IKK2. Nature 417(6891):861-866

41. Nenci A et al (2007) Epithelial NEMO links innate immunity to chronic intestinal inflammation. Nature 446(7135):557-561

42. Du J et al (2000) Glucocorticoids induce proteasome C3 subunit expression in L6 muscle cells by opposing the suppression of its transcription by NF-kappa B. J Biol Chem 275(26):19661-19666 
43. Guttridge DC et al (1999) NF-kappaB controls cell growth and differentiation through transcriptional regulation of cyclin D1. Mol Cell Biol 19(8):5785-5799

44. Judge AR et al (2007) Role for IkappaBalpha, but not c-Rel, in skeletal muscle atrophy. Am J Physiol Cell Physiol 292(1): C372-C382

45. Hunter RB, Kandarian SC (2004) Disruption of either the Nfkb1 or the $\mathrm{Bcl} 3$ gene inhibits skeletal muscle atrophy. J Clin Invest 114(10):1504-1511

46. Wang $\mathrm{H}$ et al (2007) NF-kappaB regulation of YY1 inhibits skeletal myogenesis through transcriptional silencing of myofibrillar genes. Mol Cell Biol 27(12):4374-4387

47. Bodine SC et al (2001) Identification of ubiquitin ligases required for skeletal muscle atrophy. Science 294(5547):17041708

48. Chen SE, Jin B, Li YP (2007) TNF-alpha regulates myogenesis and muscle regeneration by activating p38 MAPK. Am J Physiol Cell Physiol 292(5):C1660-C1671

49. Dogra $C$ et al (2006) Tumor necrosis factor-like weak inducer of apoptosis inhibits skeletal myogenesis through sustained activation of nuclear factor-kappaB and degradation of MyoD protein. J Biol Chem 281(15):10327-10336

50. Chen SE et al (2005) Role of TNF-\{alpha\} signaling in regeneration of cardiotoxin-injured muscle. Am J Physiol Cell Physiol 289(5):C1179-C1187

51. Langen RC et al (2004) Tumor necrosis factor-alpha inhibits myogenic differentiation through MyoD protein destabilization. FASEB J 18(2):227-237

52. Ladner KJ, Caligiuri MA, Guttridge DC (2003) Tumor necrosis factor-regulated biphasic activation of NF-kappa B is required for cytokine-induced loss of skeletal muscle gene products. J Biol Chem 278(4):2294-2303

53. Langen RC et al (2002) Tumor necrosis factor-alpha inhibits myogenesis through redox-dependent and -independent pathways. Am J Physiol Cell Physiol 283(3):C714-C721

54. Coletti D et al (2002) TNFalpha inhibits skeletal myogenesis through a PW1-dependent pathway by recruitment of caspase pathways. EMBO J 21(4):631-642

55. Collins RA, Grounds MD (2001) The role of tumor necrosis factor-alpha (TNF-alpha) in skeletal muscle regeneration. Studies in TNF-alpha(-/-) and TNF-alpha(-/-)/LT-alpha(-/-) mice. J Histochem Cytochem 49(8):989-1001

56. Layne MD, Farmer SR (1999) Tumor necrosis factor-alpha and basic fibroblast growth factor differentially inhibit the insulinlike growth factor-I induced expression of myogenin in $\mathrm{C} 2 \mathrm{C} 12$ myoblasts. Exp Cell Res 249(1):177-187

57. Li YP (2003) TNF-alpha is a mitogen in skeletal muscle. Am J Physiol Cell Physiol 285(2):C370-C376

58. Miller SC et al (1988) Tumor necrosis factor inhibits human myogenesis in vitro. Mol Cell Biol 8(6):2295-2301

59. Tracey KJ et al (1990) Metabolic effects of cachectin/tumor necrosis factor are modified by site of production. Cachectin/ tumor necrosis factor-secreting tumor in skeletal muscle induces chronic cachexia, while implantation in brain induces predominantly acute anorexia. J Clin Invest 86(6):2014-2024

60. Guttridge DC et al (2000) NF-kappaB-induced loss of MyoD messenger RNA: possible role in muscle decay and cachexia. Science 289(5488):2363-2366

61. Munz B et al (2002) RIP2, a checkpoint in myogenic differentiation. Mol Cell Biol 22(16):5879-5886
62. Yeh WC et al (1997) Early lethality, functional NF-kappaB activation, and increased sensitivity to TNF-induced cell death in TRAF2-deficient mice. Immunity 7(5):715-725

63. MacLachlan TK, Giordano A (1998) TRAF2 expression in differentiated muscle. J Cell Biochem 71(4):461-466

64. Kuroiwa $\mathrm{Y}$ et al (1996) Peg3 imprinted gene on proximal chromosome 7 encodes for a zinc finger protein. Nat Genet 12 (2): $186-190$

65. Relaix F et al (1998) Peg3/Pw1 is an imprinted gene involved in the TNF-NFkappaB signal transduction pathway. Nat Genet 18 (3):287-291

66. Relaix F et al (1996) Pw1, a novel zinc finger gene implicated in the myogenic and neuronal lineages. Dev Biol 177(2):383-396

67. Lluis $F$ et al (2006) Regulation of skeletal muscle gene expression by p38 MAP kinases. Trends Cell Biol 16(1):36-44

68. Li YP et al (2003) TNF-alpha increases ubiquitin-conjugating activity in skeletal muscle by up-regulating $\mathrm{UbcH} 2 / \mathrm{E} 220 \mathrm{k}$. FASEB J 17(9):1048-1057

69. Myung J, Kim KB, Crews CM (2001) The ubiquitin-proteasome pathway and proteasome inhibitors. Med Res Rev 21(4):245-273

70. Baeza-Raja B, Munoz-Canoves P (2004) p38 MAPK-induced nuclear factor-kappaB activity is required for skeletal muscle differentiation: role of interleukin-6. Mol Biol Cell 15(4):20132026

71. Moldawer LL et al (1987) Interleukin 1 and tumor necrosis factor do not regulate protein balance in skeletal muscle. Am J Physiol 253(6 Pt 1):C766-C773

72. Alzuherri H, Chang KC (2003) Calcineurin activates NF-kappaB in skeletal muscle C2C12 cells. Cell Signal 15(5):471-478

73. Jackman RW, Kandarian SC (2004) The molecular basis of skeletal muscle atrophy. Am J Physiol Cell Physiol 287(4): C834-C843

74. McKinnell IW, Rudnicki MA (2004) Molecular mechanisms of muscle atrophy. Cell 119(7):907-910

75. Hunter RB et al (2002) Activation of an alternative NF-kappaB pathway in skeletal muscle during disuse atrophy. FASEB J 16 (6):529-538

76. Cuthbertson D et al (2005) Anabolic signaling deficits underlie amino acid resistance of wasting, aging muscle. FASEB J 19(3): 422-424

77. Emery AE (2002) The muscular dystrophies. Lancet 359 (9307):687-695

78. Bulfield $\mathrm{G}$ et al (1984) $\mathrm{X}$ chromosome-linked muscular dystrophy (mdx) in the mouse. Proc Natl Acad Sci U S A 81 (4):1189-1192

79. Mourkioti F, Rosenthal N (2005) IGF-1, inflammation and stem cells: interactions during muscle regeneration. Trends Immunol 26(10):535-542

80. Porter JD et al (2002) A chronic inflammatory response dominates the skeletal muscle molecular signature in dystrophin-deficient mdx mice. Hum Mol Genet 11(3):263-272

81. Monici MC et al (2003) Activation of nuclear factor-kappaB in inflammatory myopathies and Duchenne muscular dystrophy. Neurology 60(6):993-997

82. Porter JD et al (2003) Persistent over-expression of specific CC class chemokines correlates with macrophage and T-cell recruitment in mdx skeletal muscle. Neuromuscul Disord 13(3):223-235

83. Acharyya $S$ et al (2007) Interplay of IKK/NF-kappaB signaling in macrophages and myofibers promotes muscle degeneration in Duchenne muscular dystrophy. J Clin Invest 117(4):889-901 
84. Baghdiguian S et al (2001) Pathophysiology of limb girdle muscular dystrophy type $2 \mathrm{~A}$ : hypothesis and new insights into the IkappaBalpha/NF-kappaB survival pathway in skeletal muscle. J Mol Med 79(5-6):254-261

85. Figarella-Branger D et al (2003) Cytokines, chemokines, and cell adhesion molecules in inflammatory myopathies. Muscle Nerve 28(6):659-682

86. Yang CC et al (1998) Immunolocalization of transcription factor NF-kappaB in inclusion-body myositis muscle and at normal human neuromuscular junctions. Neurosci Lett 254(2):77-80

87. Spencer MJ, Marino MW, Winckler WM (2000) Altered pathological progression of diaphragm and quadriceps muscle in TNF-deficient, dystrophin-deficient mice. Neuromuscul Disord 10(8):612-619

88. Rohl M et al (2004) Conditional disruption of IkappaB kinase 2 fails to prevent obesity-induced insulin resistance. J Clin Invest 113(3):474-481

89. Gilmore TD, Herscovitch M (2006) Inhibitors of NF-kappaB signaling: 785 and counting. Oncogene 25(51):6887-6899

90. Grounds MD, Torrisi J (2004) Anti-TNFalpha (Remicade) therapy protects dystrophic skeletal muscle from necrosis. FASEB J 18(6):676-682

91. Grounds MD et al (2005) Silencing TNFalpha activity by using Remicade or Enbrel blocks inflammation in whole muscle grafts: an in vivo bioassay to assess the efficacy of anti-cytokine drugs in mice. Cell Tissue Res 320(3):509-515

92. Coletti D et al (2005) Tumor necrosis factor-alpha gene transfer induces cachexia and inhibits muscle regeneration. Genesis 43 (3): $120-128$

93. Messina $\mathrm{S}$ et al (2006) Nuclear factor kappa-B blockade reduces skeletal muscle degeneration and enhances muscle function in Mdx mice. Exp Neurol 198(1):234-241
94. Balasubramanian S, Eckert RL (2007) Curcumin suppresses AP1 transcription factor-dependent differentiation and activates apoptosis in human epidermal keratinocytes. J Biol Chem 282 (9):6707-6715

95. Kang ES et al (2007) Up-regulation of aldose reductase expression mediated by phosphatidylinositol 3-kinase/Akt and Nrf2 is involved in the protective effect of curcumin against oxidative damage. Free Radic Biol Med 43(4):535-545

96. Zipper LM, Mulcahy RT (2003) Erk activation is required for Nrf2 nuclear localization during pyrrolidine dithiocarbamate induction of glutamate cysteine ligase modulatory gene expression in HepG2 cells. Toxicol Sci 73(1):124-134

97. Kopp E, Ghosh S (1994) Inhibition of NF-kappa B by sodium salicylate and aspirin. Science 265(5174):956-959

98. Amann R, Peskar BA (2002) Anti-inflammatory effects of aspirin and sodium salicylate. Eur J Pharmacol 447(1):1-9

99. Goldberg RM et al (1995) Pentoxifylline for treatment of cancer anorexia and cachexia? A randomized, double-blind, placebocontrolled trial. J Clin Oncol 13(11):2856-2859

100. Gordon JN et al (2005) Thalidomide in the treatment of cancer cachexia: a randomised placebo controlled trial. Gut 54(4):540-545

101. Girgenrath $M$ et al (2006) TWEAK, via its receptor Fn14, is a novel regulator of mesenchymal progenitor cells and skeletal muscle regeneration. EMBO J 25(24):5826-5839

102. Thaloor D et al (1999) Systemic administration of the NFkappaB inhibitor curcumin stimulates muscle regeneration after traumatic injury. Am J Physiol 277(2 Pt 1):C320-C329

103. Warren GL et al (2002) Physiological role of tumor necrosis factor alpha in traumatic muscle injury. FASEB J 16(12): $1630-1632$

104. Clinical Trials.gov Identifier:NCT00102453. Pentoxifylline in Duchenne muscular dystrophy (phase II) 